\title{
The histology of the Mitsuda reaction and its significance
}

\author{
J THOMAS, ${ }^{*}$ M JOSEPH, ${ }^{\dagger}$ K RAMANUJAM,$\ddagger$ \\ C J G CHACKO** \& $\mathrm{C} \mathrm{K} \mathrm{JOB}{ }^{\dagger \dagger}$ \\ *Postgraduate Student, Christian Medical College, Vellore; \\ $\dagger$ Medical Officer, SLR \& TC, Karigiri; $\$$ Formerly Consultant \\ Physician, SLR \& TC, Karigiri; ${ }^{* *}$ Professor of Pathology, Christian \\ Medical College, Vellore; ${ }^{\dagger}$ Professor of Pathology and Principal, \\ Christian Medical College, Vellore, NA District, Tamil Nadu
}

\section{Received for publication 25 March 1980}

\begin{abstract}
Summary The Lepromin test was done on 38 leprosy patients belonging to the various classifications of the disease. The 'delayed' or 'Mitsuda' reaction was assessed clinically and histologically at 21 days. The tuberculoid, borderline tuberculoid and all but one of the indeterminate patients showed a tuberculoid histology on Lepromin biopsy. The agreement between the histological reaction to Lepromin and the histopathology of the skin lesions was near complete in tuberculoid and borderline tuberculoid patients. In indeterminate leprosy the tissue response to Lepromin gives a clear indication of the progress of the disease in that patient. The histology of Lepromin in the lepromatous and borderline lepromatous groups was nonspecific and demonstrated large numbers of the injected bacilli. Further, in these patients minimal nodular reaction may be produced by a non-specific response of fibroblastic proliferation. In addition to the clinical reading, histologically evaluated Lepromin reaction is an important procedure to assess the immunological status of a leprosy patient.
\end{abstract}

\section{Introduction}

The development of the Lepromin test began when Yoshinubu Hayashi (1918) attempted skin testing of leprosy patients with a suspension of leprosy bacilli in Ringer's solution. He found that lepromatous patients gave few positive and many negative responses. The matter was taken up by the Japanese

Request for 'reprints should be addressed to Dr C K Job, Principal, Christian Medical College, Vellore, NA District-632 002, Tamil Nadu, S India. 
Leprologist, Kensuke Mitsuda (1919) who developed the prototype of Lepro$\min$ as it is used today and described the peculiar delayed reaction which appears at 3-4 weeks and which bears his name.

The 'late' or 'delayed' Lepromin reaction, also referred to as the 'classical' Mitsuda reaction, consists of a nodular infiltration which begins after the first week following the injection, reaches its maximum about the fourth week and later regresses, frequently leaving atrophy or a scar. Intensely strong reactions may result in ulceration (Sixth International Congress of Leprosy, 1953).

A positive Mitsuda reaction is generally equated with a pre-existing or a stimulated delayed hypersensitivity to injected antigen (Skinsnes, 1964; Meyers et al., 1975). Histologically, it consists of a dense grouping of epithelioid cells with giant cells and lymphocytes - a typical tuberculoid picture (Mitsuda, 1919; Hayashi, 1933; Schujman, 1936; Rabello \& Rotberg, 1937; Rodriguez, 1938; Fernandez, 1940; Nolasco, 1940; Rodriguez, 1950; de Faria, 1954; Neves, 1963). The negative reaction, on the other hand, may show a fibrotic, foreign body or histiocytic response (Nagai, 1940; Nolasco, 1940; Rodriguez, 1950; Azulay et al., 1960; Kuper, 1964). Epithelioid cell granulomas are absent.

The histological evaluation of the Mitsuda reaction gives an indication of the state of tissue reactivity to antigens of Mycobacterium leprae and hence is an index of the resistance of the patient to the disease. Although several workers have described the histological appearances of positive and negative Mitsuda reactions (Mitsuda, 1919; Hayashi, 1933; Schujman, 1936; Rabello \& Rotberg, 1937; Rodriguez, 1938; Fernandez, 1940; Nagai, 1940; Nolasco, 1940; Rodriguez, 1950; de Faria, 1954; Azulay et al., 1960; Neves, 1963; Kuper, 1964), to our knowledge a systematic study of the tissue response to Lepromin antigen in the entire spectrum of leprosy patients is not available. This study, therefore, attempts a detailed histological characterization of the reaction in the entire spectrum of leprosy. The relationship between the Lepromin histology and the histology of the skin lesions, the presence of the injected bacilli and the extent of agreement between the clinical and histological responses are also assessed.

\section{Materials and methods}

Thirty-eight patients were selected for the study from the Schieffelin Leprosy Research and Training Centre, Karigiri, North Arcot District. They were classified on the basis of clinical, bacteriological and histopathological criteria into five groups, according to the method of Ridley and Jopling (1966): lepromatous (resolved), 9; borderline lepromatous, 4; borderline tuberculoid, 12; tuberculoid, 4; indeterminate, 9. All the patients belonging to the lepromatous group were bacteriologically negative. 
The Lepromin test was performed using the Mitsuda - Hayashi antigen as modified by Wade (Report of the WHO Expert Committee on Leprosy, 1953). The suspension was standardized to give a bacillary concentration of $1.6 \times 10^{8}$ baccilli per millilitre. $0.1 \mathrm{ml}$ of this antigen was injected intradermally on the flex or surface of the forearm in an area free of leprosy infiltration or other skin lesions. The location of the test site with respect to anatomical landmarks was recorded.

The clinical reaction was read at the end of 21 days and graded according to the criteria adopted by the Sixth International Congress of Leprosy (1953).

All reactions whether positive or negative were biopsied. The tissue was fixed in Formol-Zenker solution for 4 hours, transferred to $70 \%$ alcohol, routinely processed and paraffin embedded. Five micron sections were stained by Haematoxylin and Eosin and by the modified Fite-Faraco method for acid-fast bacilli (Fite et al., 1947).

\section{Results}

The ages of the patients ranged from 9 to 71 years. Thirty-one of them were males and 7 females. Table 1 shows the results of the late Lepromin reaction in the various groups of patients.

TUBERCULOID GROUP

\section{Clinical readings}

At 21 days, a clinical reaction was observed in all 4 patients and varied in size from 8.0 to $21.5 \mathrm{~mm}$. Three of the nodules showed ulceration.

\section{Histological reactions}

The histology of the lepromin nodules in all 4 tuberculoid patients was characterized by the presence of large and often confluent granulomata composed of organized nodules of epithelioid cells and well-formed Langhans' giant cells bounded by a dense infiltrate of lymphocytes (Figure 1). Ulceration of the overlying epidermis was noted in three biopsies with a caseous abscess in the centre of the reaction in one of them (Figure 2) and an acute abscess in another (Figure 3). Acid-fast bacilli were not identified.

\section{BORDERLINE TUBERCULOID GROUP}

\section{Clinical readings}

In 3 of the 12 patients, the Lepromin nodules were less than $5.0 \mathrm{~mm}$ in diameter. In the remaining 9 patients, nodular reactions $5.3-18.0 \mathrm{~mm}$ in diameter were observed. Ulceration was noted in 4 of these nodules. 


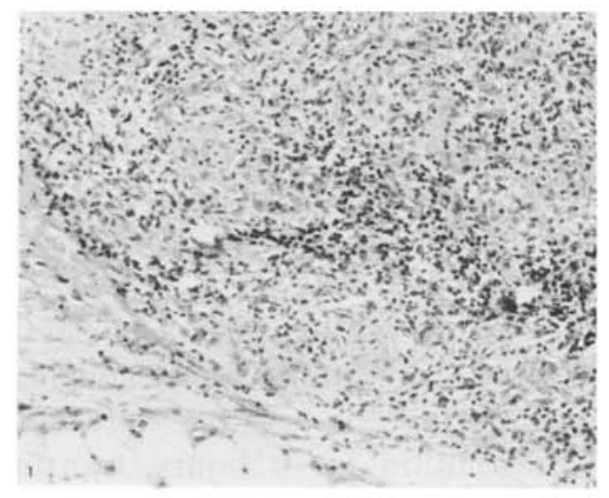

Figure 1. Tuberculoid leprosy (TT). Late Lepromin reaction. A large granuloma composed of epithelioid cells and numerous lymphocytes. H \& E $\times 480$.

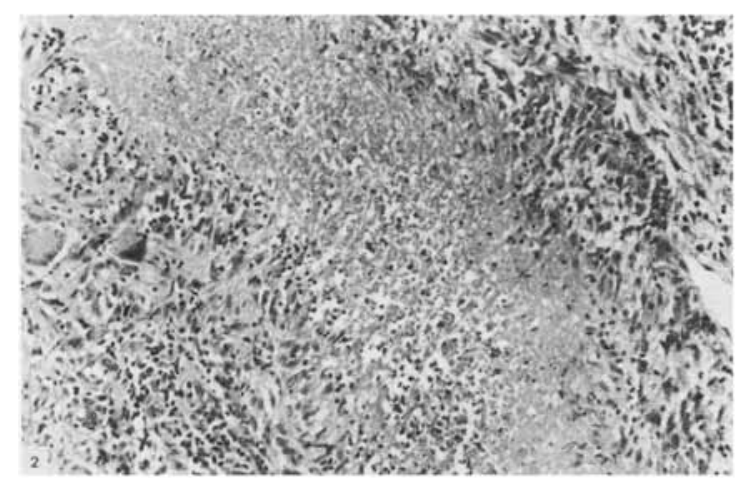

Figure 2. Tuberculoid leprosy (TT), Late Lepromin reaction. Caseous necrosis in the centre of the reaction bonded by epithelioid cells, Langhans' giant cells and lymphocytes. $\mathrm{H} \& \mathrm{E} \times 480$.

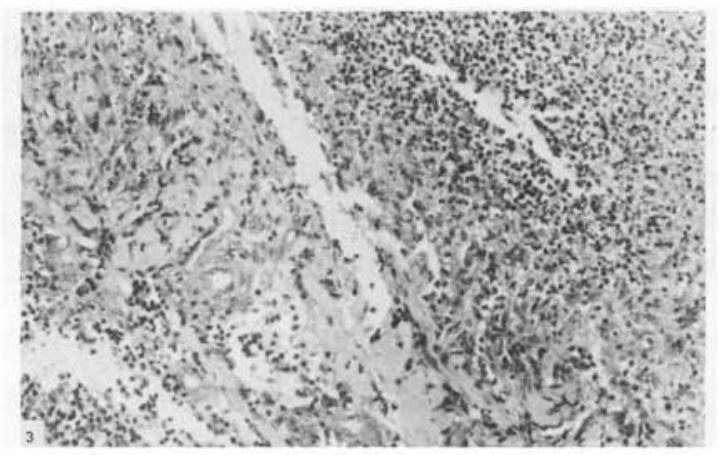

Figure 3. Tuberculoid leprosy (TT). Late Lepromin reaction. A large abscess in the centre of the reaction. Towards the periphery of the abscess numerous epithelioid cells are seen $\mathrm{H} \& \mathrm{E} \times 480$. 


\section{Histological reactions}

The histological picture was essentially uniform in all 12 biopsies and consisted of granulomata made up predominantly of epithelioid cells with variable numbers of giant cells and lymphocytes. The later were often admixed among the epithelioid cells in the granuloma (Figure 4). (The granulomas were generally smaller than those seen in the tuberculoid group. Acid-fast bacilli were not detectable in 5 patients, rare in 2 others and in the remaining 5 patients moderate numbers of bacilli were identified within the granulomas.

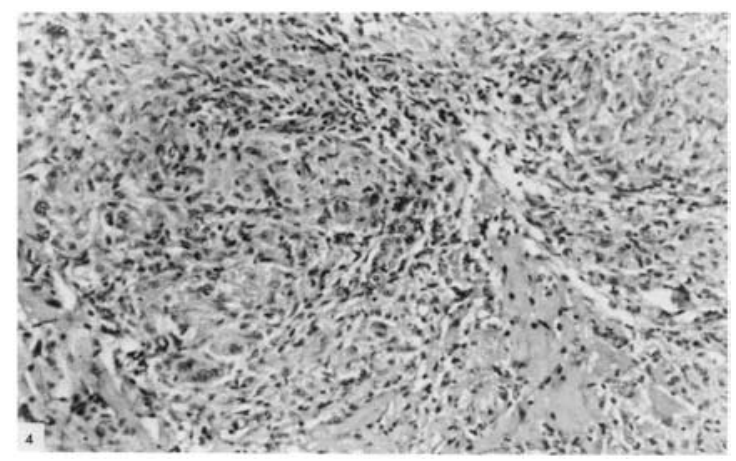

Figure 4. Borderline tuberculoid leprosy (BT). Late Lepromin reaction. Photomicrograph of the granuloma to show large collections of epithelioid cells and a few admixed lymphocytes. $\mathrm{H} \& \mathrm{E} \times 620$.

\section{BORDERLINE LEPROMATOUS GROUP}

\section{Clinical readings}

No clinical reaction was appreciated at 21 days in 2 of the 4 patients. In the 2 others, there was minimal induration less than $1.0 \mathrm{~mm}$ in diameter.

\section{Histological reactions}

A cicatricial reaction with micro-nodular proliferation of connective tissue and small aggregates of macrophages and lymphocytes was noted in 3 of the 4 biopsies (Figure 5). A few foreign-body giant cells were also present. Acid-fast bacilli were present in moderate numbers within macrophages, foreign-body giant cells and plump mononuclear cells resembling fibroblasts in the stroma. In the fourth patient belonging to this group, no histological reaction or acidfast bacilli were demonstrable at the biopsy site. 


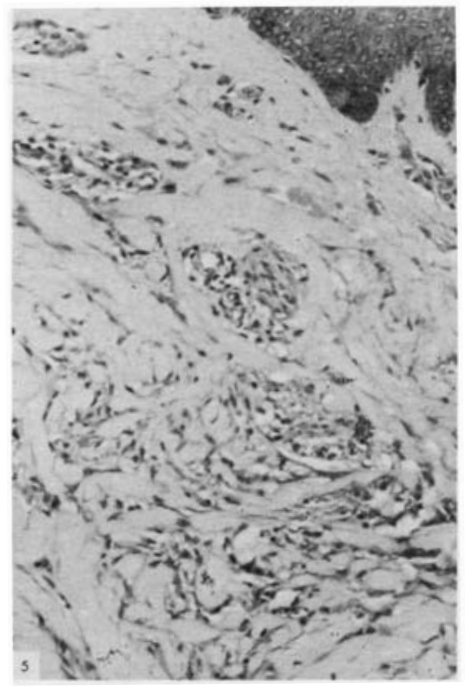

Figure 5. Borderline lepromatous leprosy (BL). Late Lepromin reaction. Diffuse fibroblastic proliferation in the dermis. $\mathrm{H} \& \mathrm{E} \times 480$.

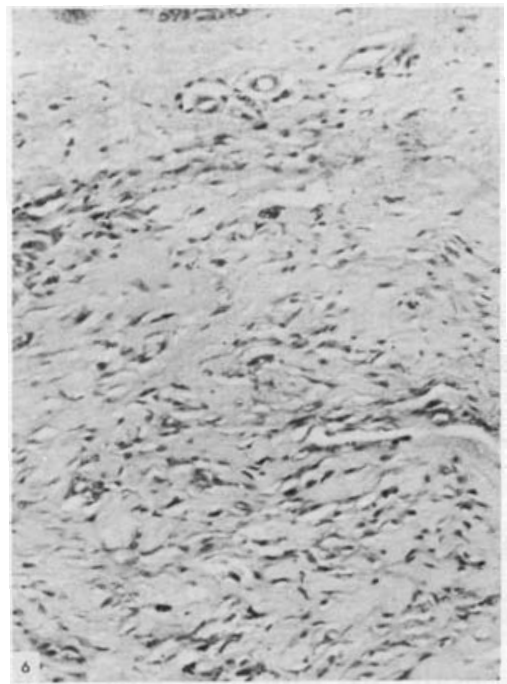

Figure 6. Lepromatous leprosy (LL). Late Lepromin reaction. Fibroblastic proliferation in the dermis. $\mathrm{H} \& \mathrm{E} \times 480$. 


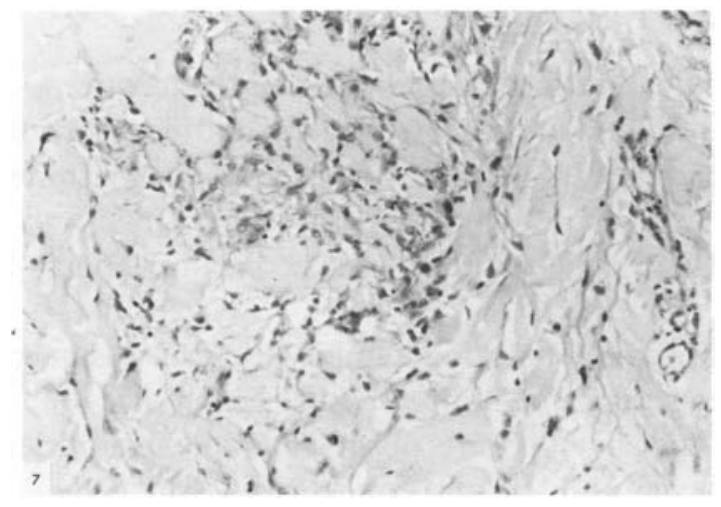

Figure 7. Lepromatous leprosy (LL). Late Lepromin reaction. Fibrotic nodule containing foreign-body giant cells. $\mathrm{H} \& \mathrm{E} \times 480$.

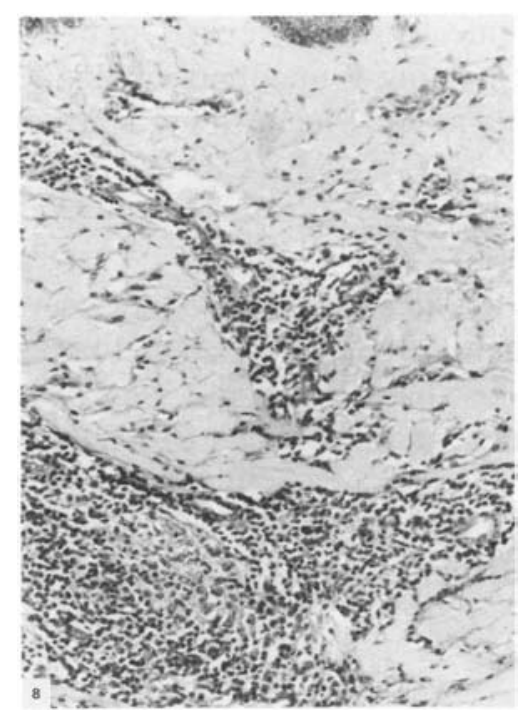

Figure 8 Lepromatous leprosy (LL). Late Lepromin reaction. Large focal aggregates of lymphocytes in the dermis. A small collection of histiocytes is also seen. H \& E $\times 480$.

\section{LEPROMATOUS GROUP}

\section{Clinical readings}

No reaction was observed in 5 patients. In the remaining 4 members of this group, there was minimal induration less than $1.0 \mathrm{~mm}$ in size. 


\section{$336 J$ Thomas et al.}

\section{Histological reactions}

A variety of histological patterns were noted in this group.

Three of the patients demonstrated micro-nodular fibroblastic proliferation with a few small aggregates of macrophages at the periphery of the fibrous nodule (Figure 6).

In two others, there were micro-nodules containing many foreign-body giant cells (Figure 7).

In the 4 remaining patients, the cellular reaction was more pronounced and consisted of focal aggregates of lymphocytes (Figure 8).

Numerous acid-fast bacilli were observed in all 9 biopsies, localized within macrophages, giant cells and stromal connective tissue cells.

\section{IN DETERMINATE GROUP}

\section{Clinical readings}

The late reaction was clinically negative in 1 patient and $3.1 \mathrm{~mm}$ in size in a second patient. In the remaining 7 members of this group, the nodules ranged from 6.5 to $15.5 \mathrm{~mm}$ in diameter. Ulceration was not noted.

\section{Histological reactions}

In 8 of the 9 patients in whom clinically, nodules were present, epithelioid cell granulomas with few giant cells and variable numbers of lymphocytes were $\mathrm{p} \quad$ (Figure 9). Acid-fast bacilli were not identified in 5 biopsies, they were scarce in 1 and in 2 others small numbers of bacilli were found in the granulomas. There was no correlation between the size of the clinical reaction and the persistence of bacilli. In the last member of this group no histological reaction or acid-fast bacilli were observed at the biopsy site.

\section{Discussion}

The 'tubercle' which has been described as the hallmark of a histologically positive late lepromin reaction is the characteristic manifestation of cellmediated immunity (Bryceson, 1976). A 'tuberculoid' response to injected lepromin is thus indicative of an effective cell-mediated immune system against antigens of Mycobacterium leprae.

The results of this study have shown that patients belonging to the polar tuberculoid group demonstrate a typical tuberculoid histology on biopsy of the late Lepromin nodules. There was also complete destruction and removal of the injected bacilli by 21 days. The reaction in the borderline tuberculoid group 


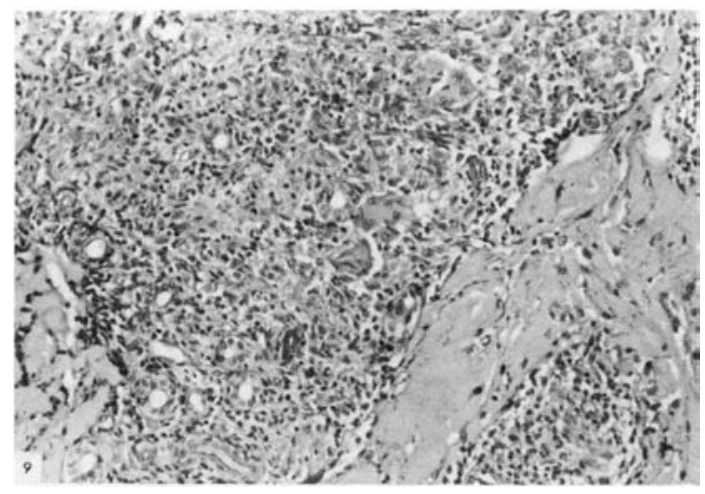

Figure 9. Indeterminate leprosy. Late lepromin reaction. A granuloma composed of epithelioid cells, giant cells and few lymphocytes, H \& E $\times 480$.

is essentially similar to that observed in tuberculoid patients with a few minor differences such as the smaller size of the granulomas and less marked lymphocytic infiltration. However, clearance of the injected bacilli was not as complete or effective as in the tuberculoid patients and persisting bacilli were observed in 7 of the 12 patients.

In the polar lepromatous group, although induration was observed clinically in some patients, the histological reaction consisting of fibroblastic proliferation, macrophages and foreign-body giant cells was non-specific in character. This indicates the importance of histological evaluation in detecting false positive clinical reactions.

Focal collections of lymphocytes were present in the biopsies from 4 of the lepromatous patients. The significance of this finding depends on whether, these lymphocytes are of the B-cell or T-cell type. If they happen to be largely T-cells, their presence would suggest a partial restoration of the cell-mediated immune response in lepromatous patients with long period of disease inactivity. , Further investigation is required to evaluate the significance of this finding.

The persistence of large numbers of the injected bacilli in all of the lepromatous patients is an expression of the extreme lack of sensitivity to the bacilli in these patients.

The Lepromin reaction in borderline lepromatous patients was very similar to the polar lepromatous group. In the borderline group of leprosy patients, the separation of the tuberculoid and lepromatous varieties is of great importance as prognosis and duration of treatment greatly differ in the two groups. The Lepromin reaction is a good and reliable ancillary confirmatory test in making this differentiation. 
Eight of the 9 patients with indeterminate leprosy demonstrated a tuberculoid histology on biopsy of the Lepromin nodule. This reaction resembled that seen in borderline tuberculoid patients and consisted of epithelioid granulomas with few giant cells and moderate lymphocytic infiltration. However, the destruction and dissolution of bacilli was variable and would reflect the degree of resistance of the patient.

In patients with indeterminate leprosy, the Lepromin reaction is of great significance as it gives an indication of how the disease would evolve if allowed to progress. In patients with a strongly positive Mitsuda reaction with characteristic tubercles and no bacilli, the disease may show spontaneous healing, remain unchanged or become tuberculoid. In contrast, those with a negative Lepromin reaction have a tendency to develop the lepromatous form of the disease (Schujman, 1953). Further, in those indeterminate patients who show tuberculoid histology in their Lepromin reactions, but many acid-fast bacilli even after 21 days, it is possible that they may progress to the lepromatous spectrum if not adequately treated.

In this study, a nodule greater than $5.0 \mathrm{~mm}$ in diameter was classified as a positive clinical reaction and it was found that in the tuberculoid, the borderline lepromatous and lepromatous groups, there was total agreement between the clinical and histological reactions. In 3 borderline tuberculoid patients and in 2 patients with indeterminate leprosy, the clinical reactions were less than $5.0 \mathrm{~mm}$ in size. However, a tuberculoid histology characterized the reactions in all 5 patients. In 2 patients with borderline lepromatous leprosy and in 4 others with lepromatous leprosy, although minimal induration was noted at the site of biopsy, the histological reactions were non-specific. The clinical reading of the Lepromin reaction, although most often reliable, may occasionally be misleading and a histological evaluation is important to confirm the positivity or the negativity of the reaction. Azulay and co-workers (1960) found agreement between macroscopic and microscopic reactions in only $75.3 \%$ of 73 positive reactors. In 2 patients, one of the indeterminate and another of the borderline lepromatous group, no bacilli or cellular reaction were seen in the Lepromin biopsy. It may be that they are negative reactions and the site was missed during biopsy in spite of all the care taken to identify the site of lepromin infection.

There is an active search for a vaccine which would protect individuals exposed to leprosy. One of the methods to find out if a person or an animal has developed immunity to leprosy and thereby determine the efficacy of the vaccine is to assess his or its reaction to lepromin before and after the administration of vaccine. In these cases, to ensure accuracy, the Lepromin reaction should be interpreted clinically and histologically. It is hoped that this histological characterization of the Lepromin reaction will increase the value of the test in the evaluation of vaccines. 


\section{References}

Azulay RD, Cezar de Andrade LM, Silva C, Netto AV, Azulay JD, Neves RG, Alonso AM (1960) Comparison of the macroscopic readings and microscopic findings of the Lepromin reaction. Int $J$ Lepr, 28, 38-43.

Bryceson ADM (1976) Immunology of leprosy. Lepr Rev, 47, 235-44.

De Faria JL (1954). Modern views on the Lepromin reaction with special consideration of its histopathology. Arch Dermat U Syph, 198, 37. Abstract in Int J Lepr, 1957, 25, 432.

Fernandez JMM $\left(1^{\mathrm{C}}+0\right)$ The early reaction induced by Lepromin. Int $J$ Lepr, 8, 1-14.

Fite GL, Cambre PJ, Turner MH, Carville BS (1947) Procedure for demonstrating lepra bacilli in paraffin sections. Arch Pathol, 43, 624.

Hayashi F (1933) Mitsuda's skin reaction in leprosy. Int J Lepr, 1, 31-8.

Hayashi Y (1918) Skin testing with leprosy bacillus suspensions. Journal of Bacteriology, 272, 51. English summary in Int $J$ Lepr, 1953, 21, 370-2.

Kuper SWA, (1964) The Lepromin reaction. In Cochrane RG, Davey TF (eds), Leprosy in Theory and Practice, 2nd ed, p. 183. Bristol: John Wright \& Sons.

Meyers WM, Kvernes S, Binford CH (1975) Comparison of reactions to human and armadillo lepromins in leprosy. Int $J$ Lepr, 43, 218.

Mitsuda K (1919) On the value of a skin reaction to a suspension of leprous nodules. Jap Derm Uro, 19, 697-708. English Translation in Int J Lepr, 1953, 21, 347-58.

Nagai K (1940) Histological findings at the sites of the Mitsuda reaction. Int J Lepr, 8, 132.

Neves R G (1963) A cytological study of the Lepromin test. Int J Lepr, 31, 577.

Nolasco JO (1940) The Lepromin test in lepra reaction. Histology of reaction lesions and persistence of injected bacilli. Int J Lepr, 8, 285-98.

Rabello JR, Rotberg (1937) Note preliminar sobre a allergia histologica na lepra. (Histologic allergy in leprosy.) Arch Dermat E Syphil São Paulo, 1, 140. English abstract in Int J Lepr, 1938, 6, 282.

Report of the WHO Expert Committee on Leprosy (1953) WHO Technical Report Series, 71,25 .

Ridley DS, Jopling WH (1966) Classification of leprosy according to immunity. A five-group system. Int $J$ Lepr, 34, 255-73.

Rodriguez J N (1938) Observations on Lepromin (Mitsuda) reaction. Int J Lepr, 6, 11-32.

Rodriguez PR (1950) The Mitsuda reaction: histopathological study. Bol Soc Cubana Dermat Sifilog, 7, 1. Abstract in Int J Lepr, 1950, 18, 442.

Schujman S (1936) Histopathology of the Mitsuda reaction in the various forms of leprosy. Rev Brasileira Leprol, 4, 469-78. Abstract in Int J Lepr, 1937, 5, 392.

Schujman S (1953) The value of the Lepromin reaction in the diagnosis of the clinical forms of leprosy. Int $J$ Lepr, 21, 313.

Sixth International Congress of Leprosy, Madrid (1953) Immunology-Lepromin reaction. Int J Lepr, 21, 531.

Skinsnes OK (1964) The immunological spectrum of leprosy. In Cochrane RG, Davey TF (eds), Leprosy in Theory and Practice, 2nd ed, p. 156. Bristol: John Wright \& Sons. 